Article

\title{
Culture growth of the cyanobacterium Phormidium sp. in various salinity and light regimes and their influence on its phycocyanin and other pigments content
}

\author{
George N. Hotos ${ }^{1 *}$
}

\author{
1 Plankton Culture Laboratory, Department of Animal Production, Fisheries \& Aquaculture \\ University of Patras, 30200 Messolonghi, Greece \\ * ghotos@upatras.gr
}

\begin{abstract}
A strain of the filamentous non N-fixing cyanobacterium Phormidium sp. isolated from the Messolonghi (W. Greece) saltworks, was cultured in the laboratory at 6 different combinations of salinity (20-40-60 ppt) and illumination (low-2000 lux and high-8000 lux). At salinities of 60 and $40 \mathrm{ppt}$ and in high illumination (XL-8000 lux) the growth rate ( $\mu$ max) presented the highest values (0.491 and 0.401 respectively) compared to the corresponding at $20 \mathrm{ppt}(0.203)$. In general and at all salinities, the higher illumination $(\mathrm{XL})$ gave the highest growth rates and shorter dublication time (tg) in comparison to the lower illumination (L). On the contrary, phycocyanin, phycoerythrin and allophycocyanin production was extremely increased in the lower illumination (L) in all salinities, from $\sim 14$ fold at 40 and $60 \mathrm{ppt}$ to 269 fold at $20 \mathrm{ppt}$ of those corresponding to higher illumination (XL). Similar analogies were also recorded for the other two billiproteins. Chlorophyll-a content was also higher in lower illumination at all salinities in contrast to total carotenoids that did not exhibit such a pattern. The high growth rate and high phycocyanin content along with the rapid sedimentation of its cultured biomass can set this marine Phormidium species as a promising canditate for mass culture.
\end{abstract}

Keywords: cyanobacteria; Phormidium; culture growth; light; salinity; phycocyanin; pigments

\section{Introduction}

Culture of microalgae has been long ago established as a much promising industry in terms of producing various value added products such as aquaculture feedstuff, bio-fuels, healthy food pills, antioxidants, pharmaceuticals, etc to name but a few of them [1-2]. The catalogue of cultured species is continuously expanded as novel species reveal advantages over others in the production yield and the economic feasibility of the culture methods employed. A huge bibliography already exists supporting the information needed in order to maximize production of the cultured species but a lot of issues still exist even for the well established culture techniques, as the whole set of parameters of culture is receptive for improvement. This is particularly true for the least studied species or for the novel ones.

Among microalgae, cyanobacteria [3] occupy a large portion of the cultured algae due mainly to the tremendous expansion of the culture of the filamentous genus Arhrospira (Spirulina) [4] that has successfully proved to be the "Holy Grail" for the worldwide production of a demanding healthy food market [5]. Production of Spirulina paved the way for expanding the spectrum of other potential mass cultured cyanobacteria of similar thallus morphology that can be to the same degree productive and can exploit other than freshwater (which is the usual case for Spirulina) waters such as brackish, seawater or even hyper-saline.

For a microalgae to be effective for production some considerations must be satisfied in order to comply for the demand of a high yield: First, a satisfactory dry mass yield per unit volume or weight, second, high levels of valuable constituents (proteins, lipids, pigments, etc) and third (but not last) ease of collection of the biomass produced. As the harvesting of the biomass remains a bottle-neck in terms of lowering the cost of production for the unicellular microalgae, this is not the case for the filamentous species such as Spirulina because its filaments tend to clump and although not a fast settler, they are easily mass gathered to be further processed. But Spirulina culture has certain drawbacks as well, concerning the prerequisites for its mass production that are: Fresh or slightly 
brackish water of a very high $\mathrm{pH}$ and high temperatures. The algae culture industry cannot be confined in freshwater only as an enormous area of the planet offers great advantages of using sites that can be supplied with water of various salinities for production of microalgae without depriving crops from irrigation water. There are other cyanobacterial species also belonging to the same order (Oscillatoriales) as Spirulina that are of filamentous nature and can thrive in saltwater. One of them Phormidium sp. (Figure 1) has been isolated [6] from the hypersaline waters ( $75 \mathrm{ppt})$ of the Messolonghi saltworks (W. Greece) and proved to be very sturdy in culture conditions producing a significant amount of phycocyanin (Figure 2).

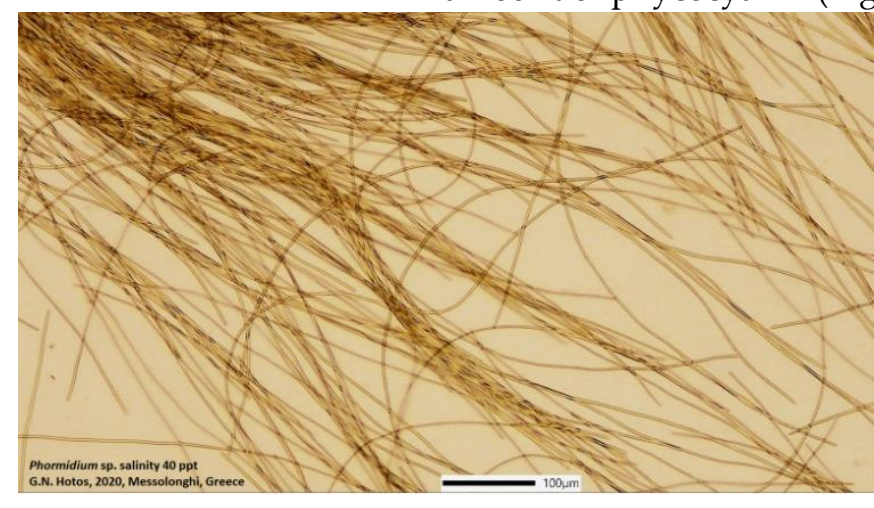

(a)

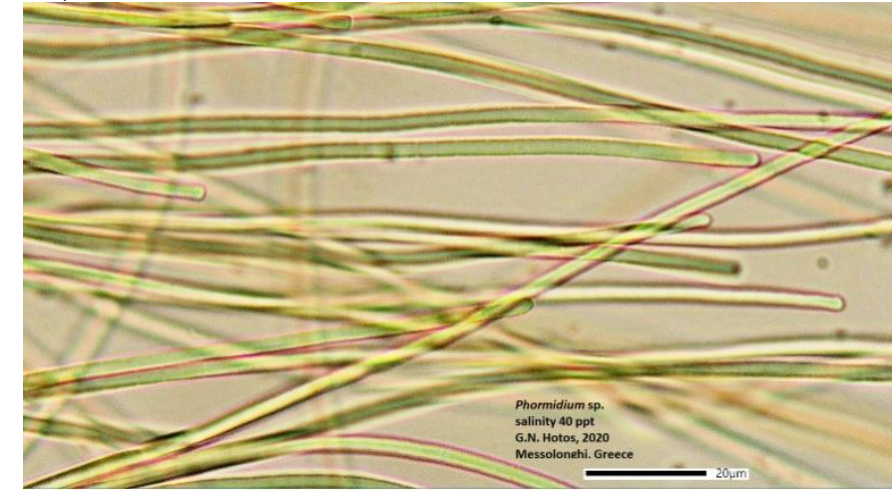

(b)

Figure 1. Filaments of Phormidium sp from culture: (a) Mass of filaments at 100x magnification; (b) Closer look at 630x magnification of the filaments of Phormidium sp.

Phycocyanin is a characteristic water soluble phycobilliprotein that abounds in cyanobacteria and in combination with phycoerythrin and allophycocyanin comprise the highly efficient photon gathering apparatus of the phycobillisomes [7]. It is blue colored and gives the characteristic bluish tint in cyanobacteria. Phycocyanin is highly valued in the market as it is a potent antioxidant for human health and a natural dye in the food industry to name but a few of its uses. On that sense, exploring the culture variables of a sturdy cyanobacterial species that can be cultured in various salinities, produces significant amount of mass, settles easily and fast enough facilitating its collection and produces significant amount of phycocyanin, deserves our attention and experimentation in order to standardize optimum protocols of culture. This is the case of the afore mentioned Phormidium sp. that follows.

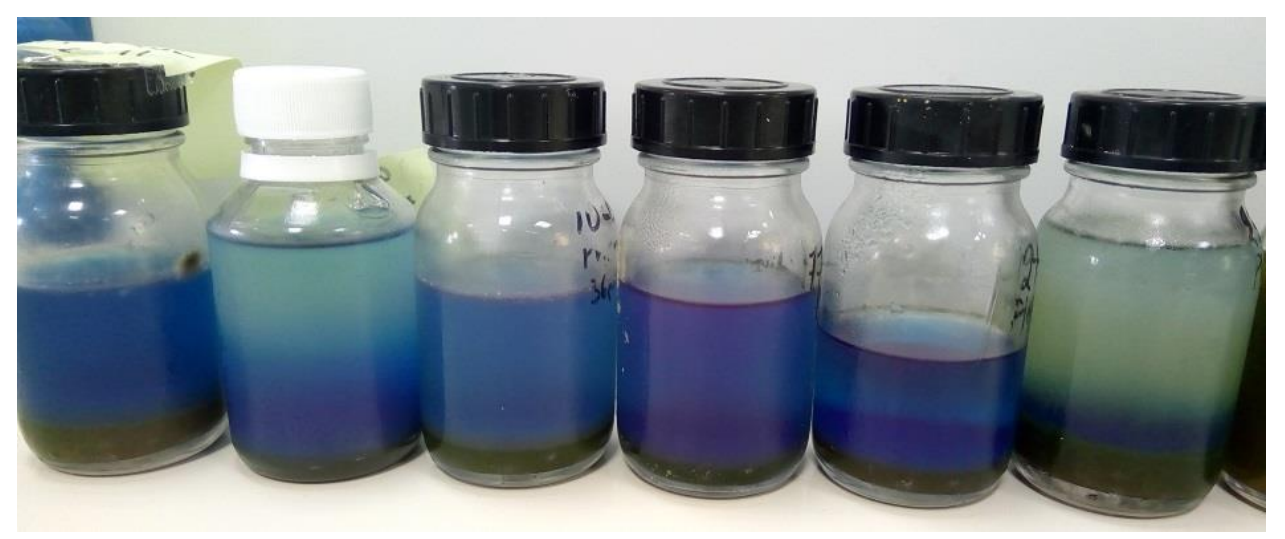

Figure 2. Samples of extracted phycocyanin after freezing and thawing of Phormidium sp. mass..

\section{Materials and Methods}

The strain of Phormidium sp. under experimentation was one of the species that ensued from a screening survey in local lagoons and saltworks of W. Greece. Through reg- 
ular renovations of cultures, Phormidium sp. dominated the culture vessel and after some more renovations its monoculture became available in a 40 ppt salinity enriched water.

The experimentation consisted of batch cultures in 2-L conical glass Erlenmeyer flasks filled with 2 liters saline water of 3 selected salinities, 20-40-60 ppt, each in triplicate receiving light intensity of 8000 lux from 20 watt 1600 lm LED lamps, measured at the middle of the outer surface of the vessel (Lux meter BIOBLOCK LX-101). Another set of the same arrangement was set in such a distance from the lamps so as to receive 2000 lux of light. The timer controlled photoperiod was kept for both sets at $16 \mathrm{hL}: 8 \mathrm{hD}$ throughout the experiment.

Prior to start, the proper amount of clean seawater (40 ppt) was autoclaved and then its salinity was adjusted properly either by dilution with sterilized distilled water (to the 20 ppt level) or by diluting sterilized artificial salt (Instant Ocean ${ }^{\circledR}$ ) in order to obtain salinity of $60 \mathrm{ppt}$. The water was enriched with minerals contained in prepared Walne's media. The suspension of the filaments and the supply of $\mathrm{CO}_{2}$ were accomplished using coarse bubbling through 2-mL glass pipettes (one in every vessel with a supply of one culture volume/min) connected through sterilized plastic hoses to the $0.45 \mu \mathrm{m}$ filtered central air supply system fed by a blower. The temperature was maintained at $21-22,5{ }^{\circ} \mathrm{C}$ by a 18,000 BTU air condition.

The progress of the cultures was monitored by daily measurements of optical density at $750 \mathrm{~nm}$ of the medium in each vessel using a visible-UV spectrophotometer (Shimadzu UVmini-1240 UV-visible-also used for pigment measurements) and transformation of the absorption values to values of $\mathrm{g}$ dry weight/L [8]. This was accomplished by using the proper equation from the calibration curve of weight vs absorbance using a dense culture of Phormidium with serial dilutions and additionally more couples of values from culture samples taken every 3 days.

The cultures of Phormidium exhibited a remarkable phenomenon of changing color from bright green in the start, turning to dark yellow around the $12^{\text {th }}-14^{\text {th }}$ day with a transient yellow-olive green tint 2-3 days before the complete change (Figure 3). This was proved a stable phenomenon occurring in all vessels and was additionally verified in subsequent cultures as well.

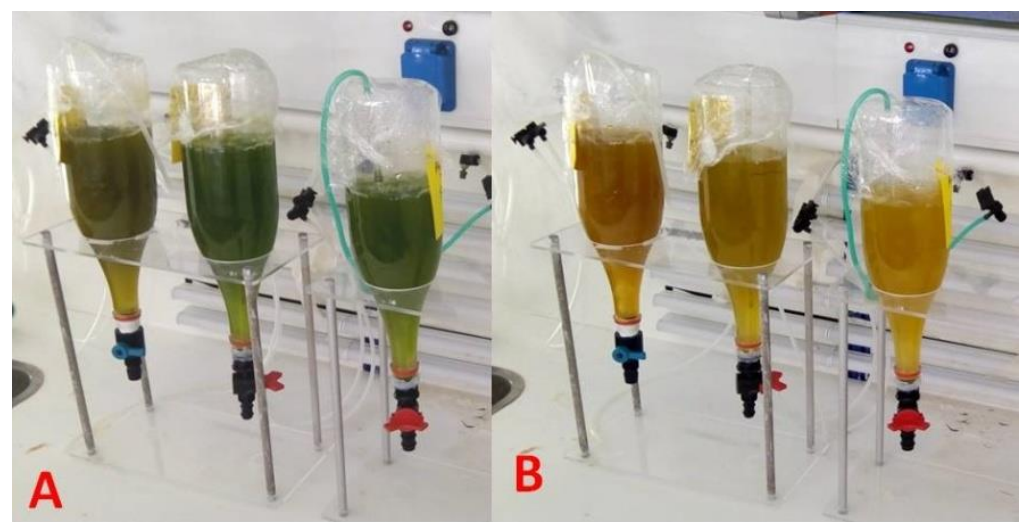

Figure 3. Coloration of Phormidium sp. mass at an early stage ( $5^{\text {th }}$ day) $(A)$ and at a late stage $\left(15^{\text {th }}\right.$ day) (B) of its culture.

When the aeration of the culture vessel stops, the mass of the filaments rapidly settles on the bottom creating a thick green or yellow mass (depending on the culture age). This highly important (for harvesting the algae) phenomenon is characteristically shown in Figure 4 and from the start till full sedimentation takes about 1 hour.

The maximum specific growth rate $\left(\mu_{\max }, \mathrm{day}^{-1}\right)$ was estimated during the exponential phase of the culture's growth curve using the equation:

$$
\mu_{\max }=\left(\ln \mathrm{C}_{2}-\ln \mathrm{C}_{1}\right) /\left(\mathrm{t}_{2}-\mathrm{t}_{1}\right)
$$

where: $C_{1}$ and $C_{2}$ stand for $g$ D.W. of cells at days $t_{1}$ and $t_{2}$ respectively (t2>t1). 
From the above equation the generation time $t_{g}$ of the culture was calculated as days for doublication using the formula:

$$
\operatorname{tg}=0.6931 / \mu \max
$$
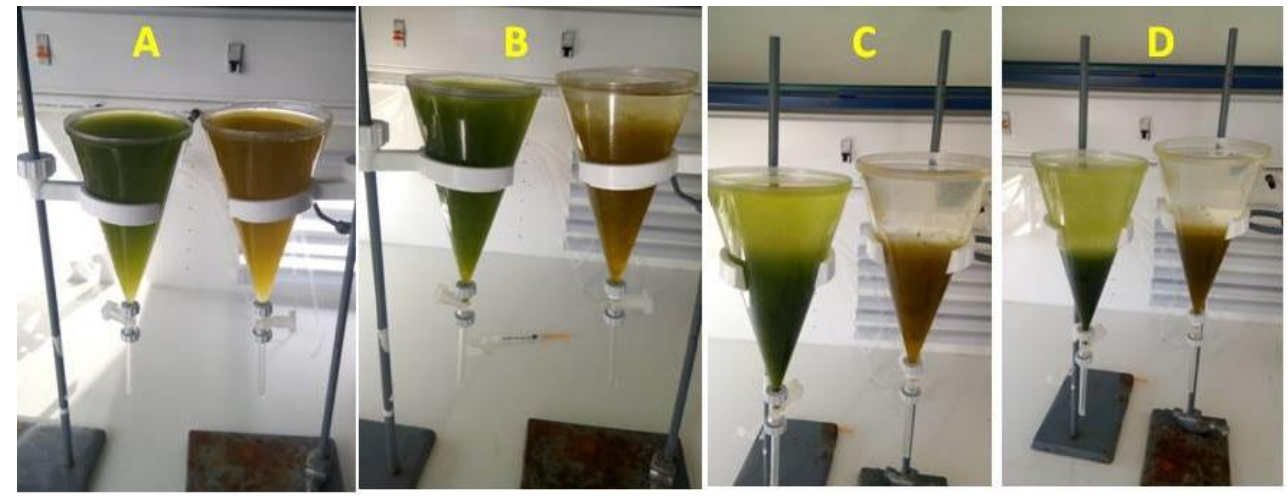

Figure 4. The progress of sedimentation of the filaments of Phormidium sp. of an early (green colored) and a late (olive-yellow) culture lasting $\sim 1$ hour between stage A and D.

The calculation of the dry weight was made by filtering a known amount of culture through $0.45 \mu \mathrm{m} \mathrm{GF/C} \mathrm{filters} \mathrm{in} \mathrm{a} \mathrm{vacuum} \mathrm{pump} \mathrm{(Heto-SUE-3Q),} \mathrm{washing} \mathrm{the} \mathrm{filter} \mathrm{with}$ ammonium formate and drying the filters in an oven to $100{ }^{\circ} \mathrm{C}$ for 2 hours. Then the filters were weighted to the $4^{\text {th }}$ decimal and the dry weight was calculated as $\mathrm{g} / \mathrm{L}$.

The $\mathrm{pH}$ was daily measured by a digital $\mathrm{pH}$-meter (HACH-HQ30d-flexi). The pigment chlorophyll-a (chl-a) was extracted using the solvent DMSO following a slightly modified method of Griffiths et al., (2011) [9] and its concentration ( $\mu \mathrm{g} / \mathrm{mL})$ was calculated spectrophotometrically using the equation:

$$
\text { chl-a }=12.47\left(\mathrm{OD}_{665}\right)-3.62\left(\mathrm{OD}_{649}\right)
$$

Total carotenoids (carot.-total) were extracted from another sample with absolute methanol [10] as solvent and their concentration $(\mu \mathrm{g} / \mathrm{mL})$ was calculated by the equations:

$$
\begin{gathered}
\text { carot.total }=\left[1000\left(\mathrm{OD}_{470}-\mathrm{OD}_{720}\right)-2.86 \mathrm{chl}-\mathrm{a}(\mu \mathrm{g} / \mathrm{ml})\right] / 221[11] \\
\text { chl-a }(\mu \mathrm{g} / \mathrm{ml})=129447\left(\mathrm{OD}_{665}-\mathrm{OD}_{720}\right)
\end{gathered}
$$

Phycocyanin (PC), allophycocyanin (APC) and phycoerythrin (PE) content were extracted by freezing $\left(-20^{\circ} \mathrm{C}\right)$ for 24 hours a concentrated known amount of cells in $0.1 \mathrm{M}$ sodium phosphate buffer ( $\mathrm{pH} 7.1$ ) as solvent at a ratio of 1:10 (algae mass:solvent) and then thawing at $4{ }^{\circ} \mathrm{C}$ in darkness. The sample's slurry was then centrifuged at $3000 \mathrm{rpm}$ for 5 minutes and the supernatant was measured spectrophotometrically to calculate the amount of the pigments (in $\mathrm{mg} / \mathrm{mL}$ ) using the equations [12]:

$$
\begin{gathered}
\mathrm{PC}=\frac{\mathrm{OD}_{615}-0.474 \mathrm{OD}_{652}}{5.34} \\
\mathrm{PE}=\frac{\mathrm{OD}_{562}-[(2.41 \mathrm{PC})-(0.849 \mathrm{APC})}{9.62} \\
\mathrm{APC}=\frac{\mathrm{OD}_{652}-0.208 \mathrm{OD}_{615}}{5.09}
\end{gathered}
$$

From the above equations the yield in phycocyanin in $\mathrm{mg} \mathrm{PC} / \mathrm{g}$ dry weight was calculated using the equation: [13].

$$
\text { PCyield }=\frac{P C\left(\frac{m g}{m L}\right) \times V(m L)}{\text { D.W. }(\mathrm{g})}
$$

Where: PCyield = mg of phycocyanin per $\mathrm{g}$ algal dry weight $\mathrm{V}=$ volume of solvent used $(\mathrm{mL})$

D.W. = grams of dry weight of the algal mass used 
Statistical treatment of the different variables was done with ANOVA and pair-wise Tukey's test for comparison of the means at the 0.05 level of significance using the free PAST3 software.

\section{Results}

The cultures were monitored for 15 days and in Figures 5-7 are depicted the growth curves along with the daily $\mathrm{pH}$ values for each set of light-salinity treatment.

In the salinity of 20 ppt (Figure 5) the cultures of both light regimes presented almost identical pattern of increase with an initial lag period of 5 days and an exponential phase from day 5 till day 12. Then the increase was lowered reaching values of $0.83 \mathrm{~g} / \mathrm{L}$ for XL and $0,77 \mathrm{~g} / \mathrm{L}$ for $\mathrm{L}$ on the $15^{\text {th }}$ day. The $\mathrm{pH}$ in the XL cultures from day 4 on was clearly kept in the high alkaline region $(>9.0)$, higher than that of the L cultures $(<9.0)$ and then after the $12^{\text {th }}$ day was reduced to almost identical values for both light regimes.

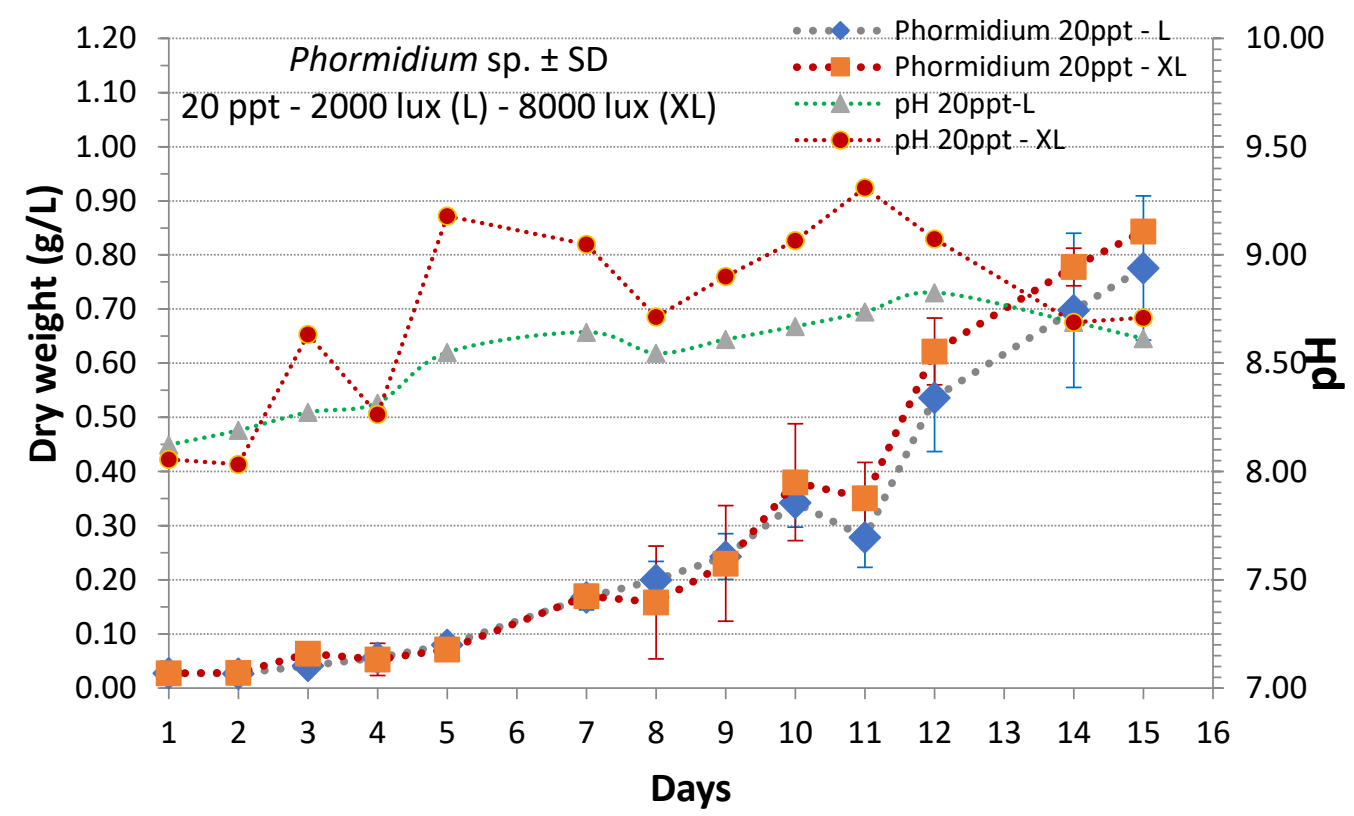

Figure 5. Growth curve and $\mathrm{pH}$ values for the period of culture of Phormidium sp. at salinity of 20 ppt in two light regimes of "high light" - "XL"- 8000 lux and "low light" - "L"- 2000 lux. 


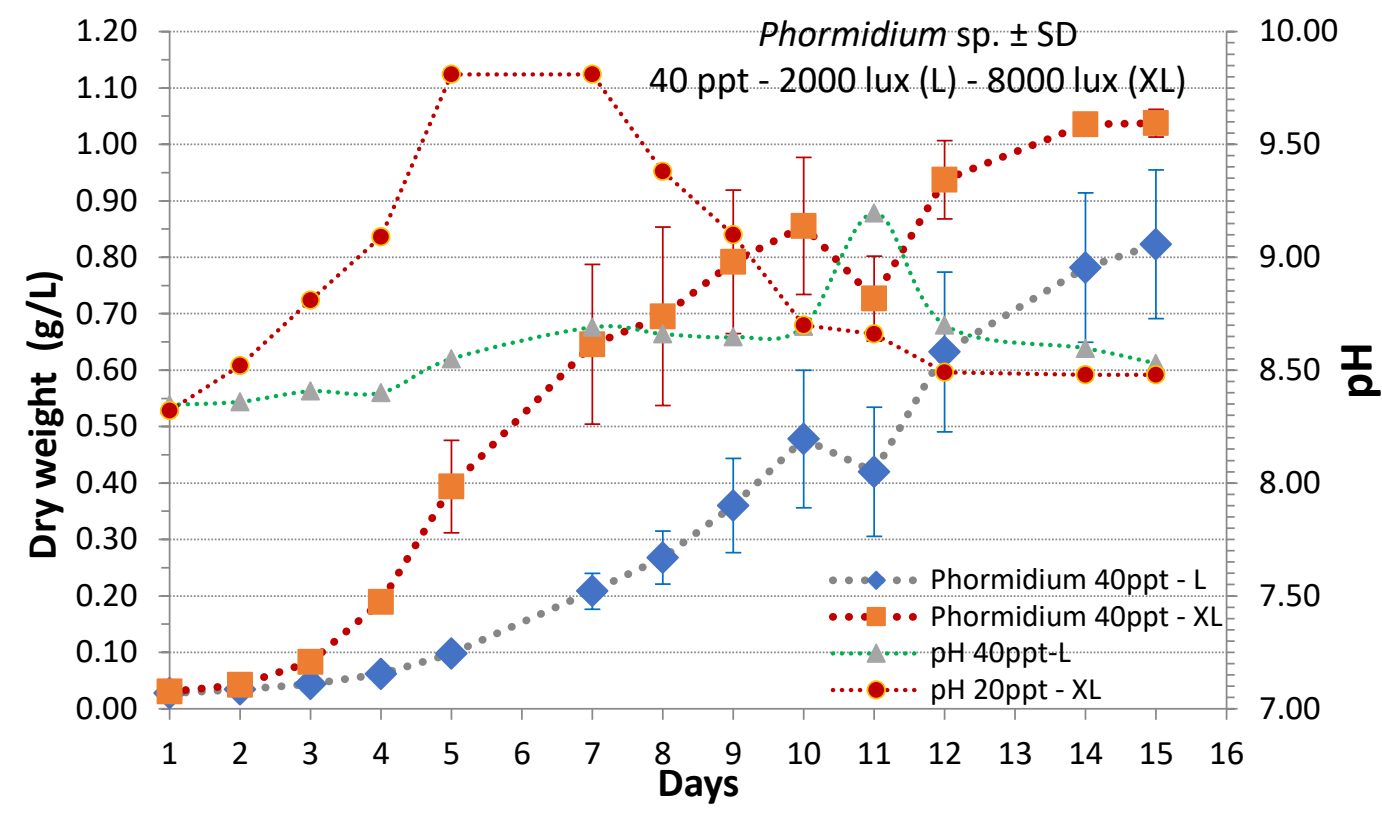

Figure 6. Growth curve and $\mathrm{pH}$ values for the period of culture of Phormidium sp. at salinity of 40 ppt in two light regimes of "high light" - "XL"- 8000 lux and "low light" - "L"- 2000 lux.

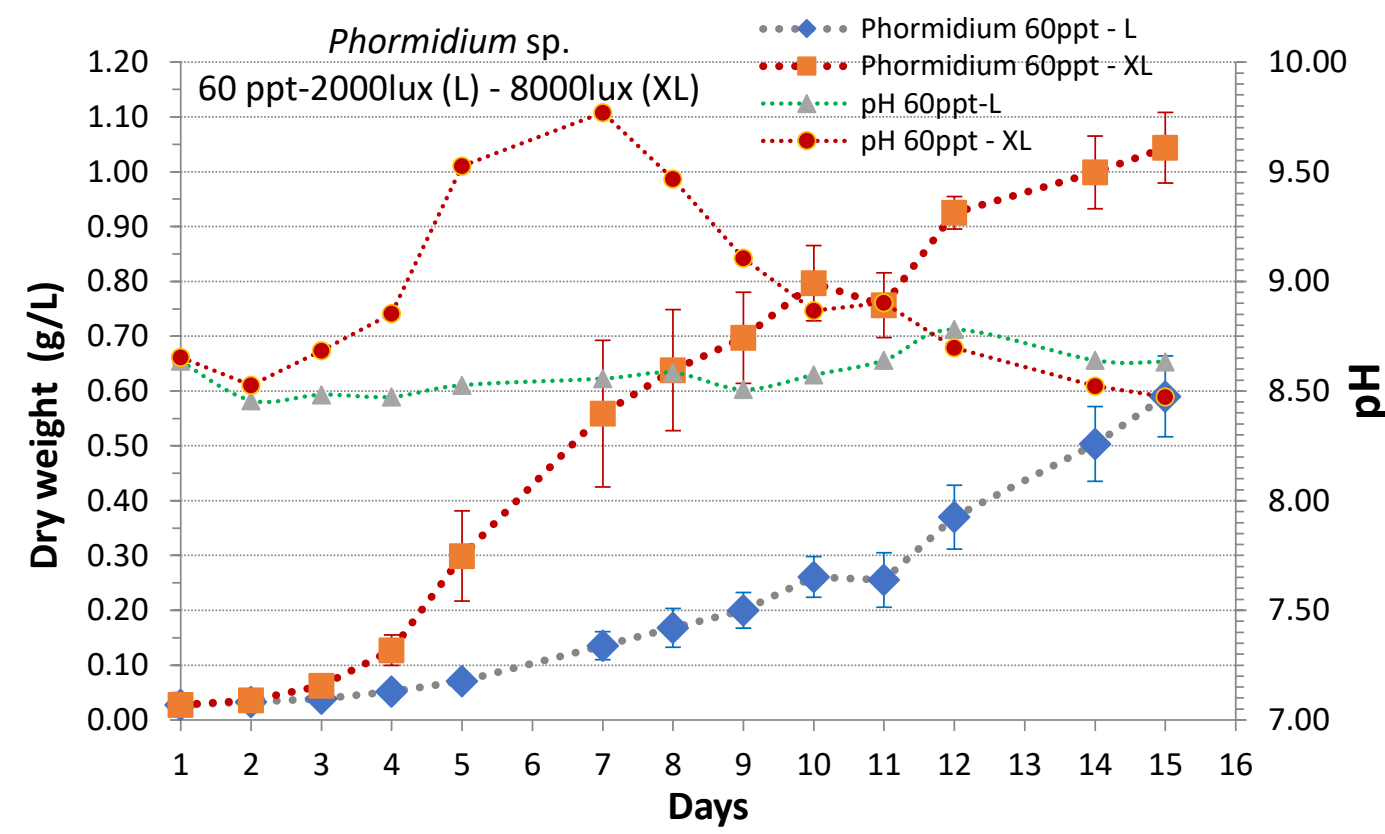

Figure 7. Growth curve and $\mathrm{pH}$ values for the period of culture of Phormidium sp. at salinity of 60 ppt in two light regimes of "high light" - "XL"- 8000 lux and "low light" - "L"- 2000 lux

In the cultures with salinities of 40 and 60 ppt (Figures 6 and 7 respectively) the initial lag phase lasted only for 3 days (as compared to 5 days in the 20 ppt cultures) for both light regimes and afterwards the growth curves entered the exponential phase which was more intense for the cultures receiving the higher level of light (XL-8000 lux), thus clearly demarcating 2 modes of growth curves, an elevated curve for high light (XL) and a substantially lower curve for the low light (L-2000 lux). This phenomenon was much more pronounced in the $60 \mathrm{ppt}$ cultures compared to the ones of $40 \mathrm{ppt}$. Basically growth was more retarded at low light and high salinityIn the $15^{\text {th }}$ day the XL cultures in both salinities attained values of $>1.00 \mathrm{~g} / \mathrm{L}$ while those of the low light (L) were at the same level as in the 20 ppt culture $(\sim 0.8 \mathrm{~g} / \mathrm{L})$ and in the relevant one of the 60 ppt even lower $(\sim 0.5 \mathrm{~g} / \mathrm{L})$.

The $\mathrm{pH}$ values in the cultures of 40 and $60 \mathrm{ppt}$ (Figures 6 and 7 respectively) exhibited a similar pattern to the cultures in $20 \mathrm{ppt}$, but here the phenomenon was much pro- 
nounced with an abrupt increase towards the high alkaline area already after the $2^{\text {nd }}$ day with the values of the $\mathrm{XL}$ cultures to reach the level of $\mathrm{pH}=9.5$ on the $7^{\text {th }}$ day and afterwards to gradually subside to values around 8.5 which characterized throughout the culture period the cultures of low light (L).

In Table 1 the growth characteristics of the cultures become more tangible with the arrangement of the values of the specific growth rate $\mu_{\max }$ and the generation time $\mathrm{tg}_{\mathrm{g}}$. The highest $\mu_{\max }(0.491)$ and the faster doubling of the algal mass $\left(\mathrm{t}_{\mathrm{g}}=1.415\right.$ days) were recorded in the culture of the highest salinity (60 ppt) and at the high level of light (XL-8000 lux) while the lowest $\mu_{\max }(0.203)$ and $\mathrm{tg}_{\mathrm{g}}(3,43$ days) in the salinity of $20 \mathrm{ppt}$ at high light (XL).

Table 1. Records of growth parameters of the cultures of Phormidium sp. in the conditions examined: $\mathrm{L}=$ light of 2000 lux, $\mathrm{XL}=$ light of 8000 lux, $\mu_{\max }=$ specific growth rate between days 4 and 7 of the culture period, $\mathrm{tg}_{\mathrm{g}}=$ days for doubling of the algal population. Values are means \pm S.D. of 27 measurements. Same or different superscripts denote non significant or significant differences respectively at the 0.05 level of confidence examined by pair-wise Tukey's test.

\begin{tabular}{ccccccc}
\hline Var. & 20ppt-L & 20ppt-XL & 40ppt-L & 40ppt-XL & 60ppt-L & 60ppt-XL \\
\hline$\mu_{\max }$ & ${ }^{\mathrm{a}} 0.363 \pm 0.03$ & ${ }^{\mathrm{b}} 0.203 \pm 0.012$ & ${ }^{\mathrm{c}} 0,404 \pm 0.045$ & ${ }^{\mathrm{a}, \mathrm{c}} 0.401 \pm 0.010$ & ${ }^{\mathrm{d}} 0.317 \pm 0.038$ & ${ }^{\mathrm{e}} 0.491 \pm 0.025$ \\
$\operatorname{tg}_{\mathrm{g}}$ & ${ }^{\mathrm{a}} 1.922 \pm 0.169^{\mathrm{b}} 3.426 \pm 0.199$ & ${ }^{\mathrm{a}, \mathrm{c}} 1.739 \pm 0.207^{\mathrm{a}, \mathrm{c}} 1.791 \pm 0.359$ & ${ }^{\mathrm{d}} 2.222 \pm 0.290$ & ${ }^{\mathrm{e}} 1.415 \pm 0,070$ \\
days & $4^{\text {th }}-7^{\text {th }}$ & $4^{\text {th }}-7^{\text {th }}$ & $4^{\text {th }}-7^{\text {th }}$ & $4^{\text {th }}-7^{\text {th }}$ & $4^{\text {th }}-7^{\text {th }}$ & $4^{\text {th }}-7^{\text {th }}$ \\
$n$ & 27 & 27 & 27 & 27 & 27 & 27 \\
\hline
\end{tabular}

All cultures were left to mature further and on the $20^{\text {th }}$ day a sample was collected from each vessel and through filtration and drying the yield in terms of dry weight per liter $(\mathrm{g} / \mathrm{L})$ was calculated as depicted in Figure 8. Yields higher than $1 \mathrm{~g} / \mathrm{L}$ were recorded in the high light cultures (XL) of 40 and 60 ppt salinities while in 20 ppt in both light regimes values were substantially lower.

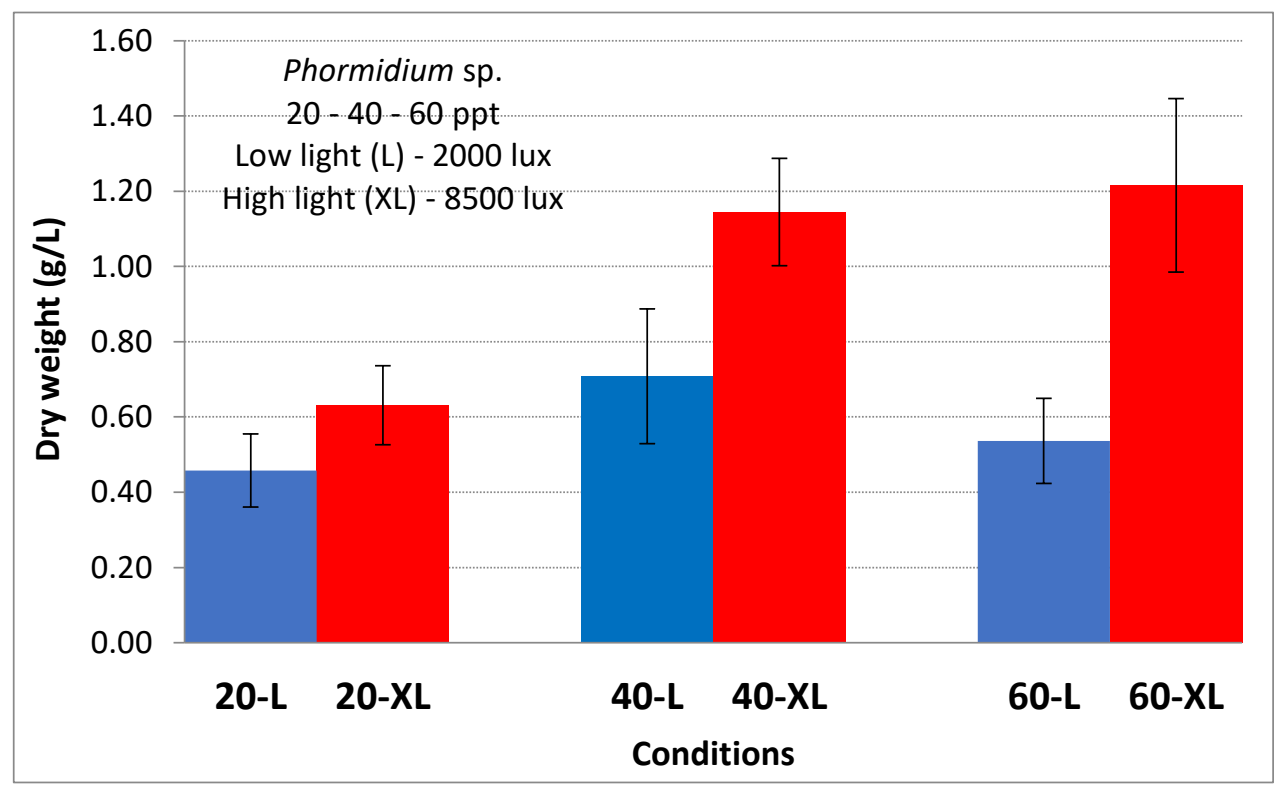

Figure 8. Yield in g dry weight per liter, of the cultures of Phormidium sp. at all treatments of combinations of salinity and illumination. Error bars represent Standard Deviation. Symbols of x-axis are explained in the caption inside the Figure.

The pigment content is summarized in Table 2. Phycobilliproteins were substantially higher both in terms of weight per culture volume $(\mathrm{mg} / \mathrm{mL})$ and weight per dry weight biomass (mg/g D.W.) in the low light regimes (L) as compared to their high light 
(XL) counterparts in all salinities, with phycocyanin content many times higher than phycoerythrin. The salinity of 20 ppt in low light (L) presented the highest yield of phycocyanin $(>20 \mathrm{mg} / \mathrm{g})$ and phycoerythrin $(>5 \mathrm{mg} / \mathrm{g})$ followed by the $60 \mathrm{ppt}$ culture and the 40 ppt culture.

Table 2. Records of pigment content in the various culture conditions. $\mathrm{PC}=$ phycocyanin in $\mathrm{mg}$ per $\mathrm{mL}$ of culture volume $(\mathrm{mg} / \mathrm{mL}), \mathrm{PC}_{\text {yield }}=$ weight of phycocyanin per biomass dry weight $(\mathrm{mg} / \mathrm{g}$ D.W.), PE = phycoerythrin $(\mathrm{mg} / \mathrm{mL})$, PEyield $=$ phycoerythrin $(\mathrm{mg} / \mathrm{mL})$, AllPC = allophycocyanin $(\mathrm{mg} / \mathrm{mL})$, Chl-a $=$ chlorophyll-a $(\mu \mathrm{g} / \mathrm{mL})$, Carot. = total carotenoids $(\mu \mathrm{g} / \mathrm{mL})$. Values are means \pm S.D. of 4 measurements. Same or different superscripts denote non significant or significant differences respectively at the 0.05 level of confidence examined by pair-wise Tukey's test.

\begin{tabular}{|c|c|c|c|c|c|c|}
\hline Var. & 20ppt-L & 20ppt-XL & 40ppt-L & 40ppt-XL & 60ppt-L & 60ppt-XL \\
\hline $\mathrm{PC}$ & $\mathrm{a} 0.277 \pm 0.061$ & ${ }^{\mathrm{b}} 0.0011 \pm 0.000$ & ${ }^{c} 0.054 \pm 0.0192$ & $\mathrm{~d} 0.0037 \pm 0.004$ & ${ }^{\mathrm{e}} 0.107 \pm 0.039$ & $\mathrm{d,f} 0.0086 \pm 0.09$ \\
\hline $\min -\max$ & $0.216-0.350$ & $0.001-0.0013$ & $0.033-0.074$ & $0.0002-0.0075$ & $0.069-0.146$ & $0.0005-0.0175$ \\
\hline $\mathrm{PC}_{\text {yield }}$ & a22.658 \pm 1.44 & ${ }^{\mathrm{b}} 0.084 \pm 0.012$ & ${ }^{c} 5.750 \pm 2.40$ & ${ }^{\mathrm{d}} 0.393 \pm 0.413$ & eg.631_0.362 & fo. $045 \pm 0.664$ \\
\hline $\min -\max$ & $21.30-24.06$ & $0.075-0.098$ & $3.428-8.001$ & $0.014-0.837$ & $9.284-10.006$ & $0.030-1.276$ \\
\hline PE & $\mathrm{a} 0.0462 \pm 0.029$ & ${ }^{b} 0.0004 \pm 0.00$ & ${ }^{c} 0.0056 \pm 0.0015$ & ${ }^{d} 0.0013 \pm 0.0009$ & ${ }^{e} 0.0107 \pm 0.0056$ & $d, f 0.0024 \pm 0.002$ \\
\hline $\mathrm{ax}$ & $0.0193-0.0744$ & 0.0004 & $0.0032-0.0073$ & $0.0002-0.0023$ & $0.005-0.0162$ & 0.0003 \\
\hline PEyield & a $3.6030 \pm 1.803$ & b $0.0307 \pm 0.001$ & ${ }^{c} 0.575 \pm 0.1641$ & $\mathrm{~d} 0.1392 \pm 0.1221$ & $\mathrm{e} 0.9662 \pm 0.1141$ & f $0.1787 \pm 0.173$ \\
\hline $\min$ & $1.9325-5.2468$ & $0.0291-0.0319$ & $0.4101-0.7311$ & $0.0148-0.2588$ & $0.8188-1.0324$ & $0.0202-0.3640$ \\
\hline AllPC & $0.1055 \pm 0.053$ & $0.0004 \pm 0.00$ & $0.0144 \pm 0.0035$ & $0.0028 \pm 0.0025$ & $0.0654 \pm 0.0641$ & $0.0058 \pm 0.006$ \\
\hline Chl-a & a8.146 0.298 & b3.457士0.136 & ${ }^{c} 6.008 \pm 0.387$ & $\mathrm{~d} 4.808 \pm 0.378$ & $\mathrm{~d}, \mathrm{e} 4.272 \pm 0.855$ & f $1.438 \pm 0.225$ \\
\hline min-max & 7.793-8.433 & 3.334-3.599 & $5.482-6.306$ & $4.274-5.164$ & $3.179-5.002$ & $1.169-1.670$ \\
\hline Carot & a2. $032 \pm 0.183$ & $\mathrm{~b} 1.210 \pm 0.026$ & c1.567士0.090 & $\mathrm{d} 1.976 \pm 0.114$ & b,c,e $1.445 \pm 0.304$ & $\mathrm{~b}, \mathrm{f} 1.153 \pm 0.274$ \\
\hline $\min -\max$ & $1.760-2.156$ & $1.186-1.245$ & $1.433-1.624$ & $1.825-2.100$ & $0.993-1.653$ & $0.747-1.331$ \\
\hline
\end{tabular}

\section{Discussion}

As the goal of an effective mass production of a certain microalgae (cyanobacterial or eukariotic) depends on its growth rate and this in turn is affected by various factors such as photoperiod, light intensity, nutrient composition, salinity, $\mathrm{pH}$, etc [14-21] , in the present study the growth rate of Phormidium sp. was investigated in 6 combinations of salinity and light intensity on the ground that these two parameters can be set clearly at certain levels and remain constant throughout the culture period. The results (Figures $5-7$, Table 1) clearly demarcated a first conclusion, that is, in elevated salinities of 40 and 60 ppt growth was far higher than in the low salinity (20 ppt) and a second conclusion nested in the first, that, with high light (8000 lux) growth was considerably higher than with low light (2000 lux) in the salinities of 40 and 60 ppt while in the lower salinity (20 ppt) the effect of light was insignificant. Although Phormidium group is far from being phylogenetically coherent [22] and considering the scarcity of data on its culture in the literature, we rely on the findings of certain species of this genus or other genera of filamentous cyanobacteria (e.g. Phormidium foveolarum, Nostoc muscorum) for a plausible explanation of the present findings. On this ground it is possible that the particular strain of Phormidium cultured here apart from being halotolerant, prefers high salinities for fast propagation. Probably in low salinity and low light suffers to a certain degree from oxidative stress while in high light the enhanced photosynthesis and the reinforced action of antioxidant enzymes compensate for or mitigate oxidative stress [23]. Similar tolerance to very high light intensity (25,000 lux) of the marine Phormidium ceylanicum was elsewhere recorded [24], probably an indication of a special physiological feature for the marine representatives of this genus that thrives even in hypersalinity [25]. Additionally, as this 
particular strain of Phormidium originated from the local salt-works, where extreme conditions of high salinity and periodically very high illumination prevail, it comes of no surprise for the findings of its higher productivity in high salinity and high light contrary to the opposite encountered in other studies (e.g. [26]). Keeping and culturing this particular strain of marine Phormidium in the laboratory for over 2 years, I am highly impressed by its ability to dominate the cultures continuously, even in occasionally neglected and old vessels or after repeating renovations and because of this, it may be one of the most promising species for maintaining monocultures. This advantage for culture of Phormidium may be probably attributed to its ability to produce some kind of allelo-chemicals [27] that suppress the growth of other cyanobacteria or eukaryotic algae (and bacteria as well), a topic quite neglected in the literature.

The observed better growth boosted by higher levels of salinity and light was also confirmed in terms of dry weight production (Figure 8), attaining values well above $1 \mathrm{~g} / \mathrm{L}$ in the $40(1.18 \mathrm{~g} / \mathrm{L})$ and $60 \mathrm{ppt}(1.22 \mathrm{~g} / \mathrm{L})$ salinities at high light illumination as compared to $0.5-0.6 \mathrm{~g} / \mathrm{L}$ in all other conditions (20 ppt both low and high light, low light at 40 and 60 ppt). As data of either growth rate or productivity on Phormidium are hardly found in the literature, because most researchers focused on its pigment content, the present study can be considered as the first of its kind creating a baseline for optimization of its mass culture conditions. The majority of relevant publications are referred to the dominant in production trials cyanobacterium Arthrospira platensis (Spirulina platensis) for which data abounds, (e.g. [28-31]). Although the existed information on Arthrospira is not presented uniformly and the conditions of the cultures employed were quite different from the present study, an attempt is made here to compare the yield of Phormidium to that of Arthrospira. For Arthrospira cultures production maxima varied from $0.2 \mathrm{~g} / \mathrm{L}$ [31] to $1.7 \mathrm{~g} / \mathrm{L}$ [30]. In this respect the present data fall in the satisfactory range of $\sim 1 \mathrm{~g} / \mathrm{L}$ which under the preferred range of salinity and light mentioned above can be easily achievable and set the basis for a routine management. Additionally, if the special dynamics in the culture of Phormidium are considered (i.e. its dominance when competes with other species in the culture vessels), then, its advantages for mass culturing are further enhanced. Industry in the algal culture section seeks for sturdy species, tolerant to extreme conditions, stability of culture, fast growth rate and satisfactory production of dry mass. Last, but may be most important, simple and easy collection of the algal mass. In this respect Phormidium has a tremendous advantage over other microalgae, as it settles completely (Figure 4) after about an hour from the stopping of aeration.

The second aim of the present study deals with the cellular content in phycocyanin and other pigments in order to find the optimum conditions for maximizing the output of these highly valued and highly commercialized substances. The results exhibited a profound production of phycocyanin, far bigger in the low light condition compared to high light. This was recorded in all salinities tested but its most outstanding expression was in the lower salinity of 20 ppt where in the low light the phycocyanin amount both in terms of concentration or yield $(0.277 \mathrm{mg} / \mathrm{mL}$ and $22.658 \mathrm{mg} / \mathrm{g} \mathrm{DW}$ respectively) was 250 times more than the relevant values recorded in the high light $(0.0011 \mathrm{mg} / \mathrm{mL}$ and $0.084 \mathrm{mg} / \mathrm{g}$ DW respectively). In the other 2 salinities (40 and $60 \mathrm{ppt}$ ) the same situation (higher production of phycocyanin in low light vs high light) occurred, although not in the same exaggerated manner as in 20 ppt but nevertheless impressively intense with ratios of $\sim 14: 1$ (L:XL).

The same pattern was recorded also for the other two billiproteins (phycoerythrin and allophycocyanin) with outstanding higher amounts produced in low light of all salinities vs high light. The phenomenon was also much pronounced in the lower salinity of 20 ppt where the ratios were 115:1 (L:XL) for phycoerythrin and 263:1 for allophycocyanin as compared to $\sim 4.5: 1$ for phycoerythrin and 5-11:1 for allophycocyanin in the higher salinities of 40 and 60 ppt.

Such data clearly indicate towards the catalytic effect of the lower illumination to the enhancement of cellular production of billiproteins. As a number of cyanobacterial species has been screened on their ability to produce phycocyanin [32] and significant 
amounts of other pigments (chlorophylls, carotenoids) [33], the spectrum of their cellular content in all species (depended on the conditions prevailing) is very wide [34-36] and insinuates that the mechanization related to the proper manipulations of the cultures to achieve the desired production is widely open for improvement.

Attempting to compare the data on phycocyanin and on the other two billiproteins of the present study with those of the literature, rather few and fragmented data on Phormidium and other cyanobacteria can be found. However the influence of low level of irradiance on increased phycocyanin production of Phormidium foveolarum and of Nostoc muscorum [23] was in accordance with the present data. Considering that billiproteins along with carotenoids (also present in cyanobacteria) constitute the accessory pigments of these algae [37], helping in maximizing photons capture when feeble illumination prevails, while in other sunlit environments shift roles protecting the photosystems from photolysis, an assumption (for cyanobacteria) based on evidence can be made. That is, billiproteins have the sole mission to gather the maximum amount of light possible. As of this, in conditions of inadequate levels of light for maximum photosynthesis, the cell initiates excessive production of phycocyanin (mainly) and phycoerythrin-allophycocyanin accordingly. On the other hand, carotenoids have double mission, light gathering and photo-protection, both of which affect their cellular concentration but in a less pronounced mode than that of billiproteins. Data from the literature on that topic are rather puzzling, as they are noting an increase of carotenoids in high light $[23,38]$ in species of Phormidium, Nostoc and Anabaena contrary to the case in the present study where there were not recorded great differences in carotenoids between low and high light in all 3 salinities tested (Table 2), with the biggest difference recorded in the lower salinity of 20 ppt, $2.032 \mu \mathrm{g} / \mathrm{mL}$ vs $1.210 \mu \mathrm{g} / \mathrm{mL}$ (L vs XL). On the other hand chlorophyll-a content was much increased at all salinities in low light as compared to high light (Table 2) with the biggest values recorded in the lower salinity (20 ppt).

Summarizing all the above, concerning the pigment content of this particular strain of Phormidium as affected by different light and salinity regimes, a profound influence of the low level of illumination on the increase of billiproteins and chlorophyll cell content was beyond any doubt recorded. This was much exaggerated in the lower salinity which bring us now to consider the influence of salinity on the cellular pigment content. The increased level of carotenoids recorded at $60 \mathrm{ppt}$ for the coccoid cyanobacterium Synechocystis sp. PCC 6803 [39] was not the case in the present study where carotenoids more or less remained at similar levels in all salinities. It can be probably attributed to differences among species regarding their tolerance and adaptation ability to various salinities. But when phycocyanin is concerned, contrary to some studies in which a considerable drop in the phycocyanin content and overall photosynthesis was recorded when cultured in high salinity (60 ppt), attributable to the induced damage on phycobillisomes [40] or on proteins of the PS II reaction center [41,42] of Spirulina platensis and Synechococcus sp. respectively, the present study suggests the opposite for Phormidium. This can be probably attributed to the special physiology of this species that seems to grow better in high salinities (not to forget that was originated from salt-works). The evidence for an elevated rate of photosynthesis in higher salinities (thus faster growth), is also validated by the more alkaline $\mathrm{pH}$ in the conditions of high light at 40 and $60 \mathrm{ppt}$ salinities due probably to an elevated rate of subtraction of protons from water [43] (and not to a reduction in $\mathrm{CO}_{2}$ which anyway was constantly supplied by aeration) in order to enhance NADPH levels for more sugar production.

Summing up the data on culture growth and phycocyanin output in order to construct a competitive production scheme for this novel high salt preferring species of Phormidium, the following process is advised:

1. Culture of the cyanobacterium with Walne's medium enriched water of over 40 ppt salinity (suggested range 40-60 ppt), with light intensity of 8000 lux or more for about 15 days in order to enhance best biomass production.

2. Stopping of aeration and initiation of filament's sedimentation, which takes about an hour after which the dense settled biomass can be collected. To facilitate the sedi- 
mentation and collection of algal biomass it is advised to use transparent tubular culture vessels preferably with a conical bottom. After the completion of sedimentation the supernatant is discarded.

3. The collected wet biomass is transferred to new culture vessels filled with fresh nutrient enriched water of 20 ppt salinity, lit by LED lamps producing no more than 2000 lux metered on the surface of the vessels, in order to maximize phycocyanin production. Aeration supplied to the vessels should be continuous at a rate of about one culture volume of air per minute.

Funding: This research was financially supported by the research program "ALGAVISION: Isolation and culture of local phytoplankton species aiming to mass production of antibacterial substances, fatty acids, pigments and antioxidants" (MIS 5048496), funded by the General Secretariat of Research and Technology of the Greek Government.

Acknowledgments: The author thanks the technical staff of the laboratory Ms Despoina Avramidou and Ms Athina Samara for their help in experimentation thanks also to Mr. Theodoros Antoniadis for pigment measurements.

Conflicts of Interest: The authors declare no conflict of interest. The funders had no role in the design of the study; in the collection, analyses, or interpretation of data; in the writing of the manuscript, or in the decision to publish the results.

\section{References}

1 Priyadarshani, I., Rath, B. Commercial and industrial applications of micro algae - A review. J. Algal Biomass Utln. 2012, 3 (4): 89-100.

2 Sun, H., Zhao, W., Mao, X., Li, Y., Wu, T., Chen, F. High-value biomass from microalgae production platforms: strategies and progress based on carbon metabolism and energy conversion. Biotechnol Biofuels 2018, Aug 20:11:227. doi: 10.1186/s13068-018-1225-6.

3 Pathak, J., Rajneesh, M.P.K. Singh, S.P., Häder, D.P., Sinha, R.P. Cyanobacterial Farming for Environment Friendly Sustainable Agriculture Practices: Innovations and Perspectives. Front. Environ. Sci. 2018, 6(7): 1-13. doi: 10.3389/fenvs.2018.00007.

4 Saranraj, P., Sivasakthi, S. Spirulina platensis-Food for future: A review. Asian Journal of Pharmaceutical Science \& Technology 2014, 4(1): 26-33.

5 Spolaore, P., Joannis-Cassan, C., Duran, E., Isambert, A. Commercial applications of microalgae. J. Biosci. Bioeng. 2006, 101(2): 87-96. https://doi.org/10.1263/jbb.101.87.

6 Hotos, G.N. A Preliminary Survey on the Planktonic Biota in a Hypersaline Pond of Messolonghi Saltworks (W. Greece). Diversity 2021, 13, 270. https://doi.org/10.3390/d13060270

7 Eriksen, N.T. Production of phycocyanin-a pigment with applications in biology, biotechnology, foods and medicine. Appl. Microbiol. Biotechnol. 2008, 80(1): 1-14. doi: 10.1007/s00253-008-1542-y.

8 Hotos, G. N., Avramidou, D., Bekiari, V. Calibration Curves of Culture Density Assessed by Spectrophotometer for Three Microalgae (Nephroselmis sp., Amphidinium carterae and Phormidium sp.). European Journal of Biology and Biotechnology 2020, 1(6): 1-7. https://doi.org/10.24018/ejbio.2020.1.6.132

9 Griffiths, M.J., Garcin, C., van Hille, R.P., Harrison, S.T. Interference by pigment in the estimation of microalgal biomass concentration by optical density. J. Microbiol. Methods. 2011, 85(2): 119-23. doi: 10.1016/j.mimet.2011.02.005.

10 Zavřel, T., Sinetova, M. A., Červený, J. Measurement of Chlorophyll a and Carotenoids Concentration in Cyanobacteria. Bio-protocol 2015, 5(9): e1467. DOI: 10.21769/BioProtoc.1467.

11 Wellburn, A. R. The spectral determination of chlorophyll a and chlorophyll b, as well as total carotenoids, using various solvents with spectrophotometers of different resolution. Journal of Plant Physiology 1994, 144 (3): 307-313. ISSN 1618-1328.

12 Arashiro, L.T., Boto-Ordóñez, M., Van Hulle, S.W.H., Ferrer, I., Garfí, M., Rousseau, D.P.L. Natural pigments from microalgae grown in industrial wastewater. Bioresour. Technol. 2020, May;303:122894. doi: 10.1016/j.biortech.2020.122894.

13 Moraes, C.C., Sala, L., Cerveira, P. G. , Kalil, J. S. C-Phycocyanin extraction from Spirulina platensis wet biomass. Brazilian Journal of Chemical Engineering 2011, 28(1): 45-49. ISSN: 0104-6632.

14 Rao, A.R., Dayananda, C., Sarada, R., Shamala, T.R., Ravishankar, G.A. Effect of salinity on growth of green alga Botryococcus braunii and its constituents. Bioresour. Technol. 2007, 98(3): 560-564. doi: 10.1016/j.biortech.2006.02.007.

15 Groom, M.J., Gray, E.M., Townsend, P.A. Biofuels and biodiversity: principles for creating better policies for biofuel production. Conserv Biol. 2008, Jun;22(3): 602-9. doi: 10.1111/j.1523-1739.2007.00879.x. 
16 Kitaya, Y., Xiao, L., Masuda, A., Ozawa, T., Tsuda, M., Omasa, K. Effects of temperature, photosynthetic photon flux density, photoperiod and $\mathrm{O}_{2}$ and $\mathrm{CO}_{2}$ concentrations on growth rates of the symbiotic dinoflagellate, Amphidinium sp.. J. Appl. Phycol. 2008, 20: 737-742. DOI 10.1007/s10811-008-9331-7.

17 Mata, T. M., Martins, A. A., Caetano, N. S., Microalgae for biodiesel production and other applications: A review. Renewable and Sustainable Energy Reviews 2010, 14(1): 217-232. https://doi.org/10.1016/j.rser.2009.07.020.

18 Xue, S., Su, Z., Cong, W. Growth of Spirulina platensis enhanced under intermittent illumination. J Biotechnol. 2011, Feb 10;151(3): 271-7. doi: 10.1016/j.jbiotec.2010.12.012.

19 Parmar, A., Singh, N.K., Pandey, A., Gnansounou, E., Madamwar, D. Cyanobacteria and microalgae: a positive prospect for biofuels. Bioresour Technol. 2011 Nov;102(22): 10163-72. doi: 10.1016/j.biortech.2011.08.030.

20 Ho, S.H., Huang, S.W., Chen, C.Y., Hasunuma, T., Kondo, A., Chang, J.S. Characterization and optimization of carbohydrate production from an indigenous microalga Chlorella vulgaris FSP-E. Bioresour. Technol. 2013, May;135: 157-65. doi: 10.1016/j.biortech.2012.10.100.

21 Wahidin, S., Idris, A., Shaleh, S.R. The influence of light intensity and photoperiod on the growth and lipid content of microalgae Nannochloropsis sp. Bioresour Technol. 2013, Feb;129: 7-11. doi: 10.1016/j.biortech.2012.11.032.

22 Marquardt, J., Palinska, K.A. Genotypic and phenotypic diversity of cyanobacteria assigned to the genus Phormidium (Oscillatoriales) from different habitats and geographical sites. Arch. Microbiol. 2007, May;187(5): 397-413. doi: 10.1007/s00203-006-0204-7.

23 Kumar, J., Singh, V.P., Prasad, S.M. NaCl-induced physiological and biochemical changes in two cyanobacteria Nostoc muscorum and Phormidium foveolarum acclimatized to different photosynthetically active radiation. J. Photochem. Photobiol. B. 2015, Oct;151: 221-232. doi: 10.1016/j.jphotobiol.2015.08.005.

24 Bhandari, R., Sharma, P.K. High-light-induced changes on photosynthesis, pigments, sugars, lipids and antioxidant enzymes in freshwater (Nostoc spongiaeforme) and marine (Phormidium corium) cyanobacteria. Photochem. Photobiol. 2006, 82(3): 702-10. doi: 10.1562/2005-09-20-RA-690.

25 Nagasathya, A., Thajuddin, N. Cyanobacterial Diversity in the Hypersaline Environment of the Saltpans of Southeastern Coast of India. Asian Journal of Plant Sciences 2008, 7: 473-478. https://dx.doi.org/10.3923/ajps.2008.473.478.

26 Rosales, N., Ortega, J., Mora, R., Morales, E. Influence of salinity on the growth and biochemical composition of the cyanobacterium Synechococcus sp. Ciencias Marinas 2005, 31(2): 349 - 355. http://dx.doi.org/10.7773/cm.v31i2.59.

27 Dias, F., Antunes, J.T., Ribeiro, T., Azevedo, J., Vasconcelos, V., Leão, P.N. Cyanobacterial Allelochemicals But Not Cyanobacterial Cells Markedly Reduce Microbial Community Diversity. Front. Microbiol. 2017, Aug 8;8:1495. doi: 10.3389/fmicb.2017.01495.

28 Silveira, S.T., Burkert, J.F., Costa, J.A., Burkert, C.A., Kalil, S.J. Optimization of phycocyanin extraction from Spirulina platensis using factorial design. Bioresour. Technol. 2007, May;98(8): 1629-34. doi: 10.1016/j.biortech.2006.05.050.

29 Göksan, T., Zekeriyaoğlu, A., Ak, I. The Growth of Spirulina platensis in Different Culture Systems under Greenhouse Condition. Turkish Journal of Biology, 2006, 31: 47-52.

30 Pandey, J. P., Pathak, N., Tiwari, A. Standardization of $\mathrm{pH}$ and Light Intensity for the Biomass Production of Spirulina platensis. Journal of Algal Biomass Utilization 2010, 1(2): 93-102.

31 Walter A., de Carvalho, J. C., Soccol, V. T., Bisinella de Faria, A. B., Ghiggi, V., Soccol, C. R. Study of Phycocyanin Production from Spirulina platensis Under Different Light Spectra. Brasilian Archives of Biology and Technology 2011, 54(4): 675-682. https://doi.org/10.1590/S1516-89132011000400005.

32 Singh, N.K., Parmar, A., Madamwar, D. Optimization of medium components for increased production of C-phycocyanin from Phormidium ceylanicum and its purification by single step process. Bioresour. Technol. 2009, 100(4): 1663-1669. doi: 10.1016/j.biortech.2008.09.021.

33 Rodrigues, D.B., Menezes, C. R., Mercadante, A. Z., Jacob-Lopes, E., Zepka, L. Q. Bioactive pigments from microalgae Phormidium autumnale. Food Research International 2015, 77(2): 273-279. https://doi.org/10.1016/j.foodres.2015.04.027.

34 Healey, F.P.. Physiological indicators of nutrient deficiency in algae. Fish. Mar. Serv. Res. Dev. Tech. Rep. 1975, 585: 30 p.

35 Nicholls, K.H., Dillon, P.J. An Evaluation of Phosphorus-Chlorophyll-Phytoplankton Relationships for Lakes. Hydrobiol. 1978, 63(2): 141-154. https://doi.org/10.1002/iroh.19780630203.

36 Walsby, A. Microalgae: Biotechnology and Microbiology. Experimental Agriculture 1995, 31(1): 112-112. doi:10.1017/S0014479700025126.

37 Fresnedo, O., Gomez, R., Serra, J.L. Carotenoid composition in the cyanobacterium Phormidium laminosum. Effect of nitrogen starvation. FEBS Lett. 1991, May 6;282(2): 300-4. doi: 10.1016/0014-5793(91)80500-3

38 Gao, K., Yu, H., Brown, M.T. Solar PAR and UV radiation affects the physiology and morphology of the cyanobacterium Anabaena sp. PCC 7120. J. Photochem. Photobiol. B. 2007, Dec 14;89(2-3): 117-24. doi: 10.1016/j.jphotobiol.2007.09.006.

39 Schubert, H., Fulda, S., Hagemann, M. Effects of adaptation to different salt concentrations on photosynthesis and pigmentation of the cyanobacterium Synechocystis sp. PCC 6803. J. Plant Physiol. 1993, 142(3): 291-295. doi: 10.1016/S0176-1617(11)80425-6.

40 Lu, C., Vonshak, A. Effects of salinity stress on photosystem II function in cyanobacterial Spirulina platensis cells. Physiol Plant. 2002, Mar;114(3): 405-413. doi: 10.1034/j.1399-3054.2002.1140310.x.

41 Murata, N., Miyao, M.. Extrinsic membrane proteins in the photosynthetic oxygen-evolving complex. Trends Biochem. Sci. 1985, 10(3): 122-124. https://doi.org/10.1016/0968-0004(85)90272-5. 
42 Parida, A., Das, A., Mittra, B. Effects of $\mathrm{NaCl}$ Stress on the Structure, Pigment Complex Composition, and Photosynthetic Activity of Mangrove Bruguiera parviflora Chloroplasts. Photosynthetica 2003, 41(2): 191-200. https://doi.org/10.1023/B:PHOT.0000011951.37231.69.

43 Zerveas, S., Mente, M.S., Tsakiri, D., Kotzabasis, K. Microalgal photosynthesis induces alkalization of aquatic environment as a result of $\mathrm{H}+$ uptake independently from $\mathrm{CO} 2$ concentration - New perspectives for environmental applications. J Environ Manage. 2021, Jul 1;289: 112546. doi: 10.1016/j.jenvman.2021.112546. 